\title{
Effect of Cornus Mas L. Fruit Extract on Blood Pressure, Anthropometric and Body Composition Indices in Patients with Non-Alcoholic Fatty Liver Disease: A Randomized Controlled Trial
}

\section{Faezeh Yarhosseini}

Shahid Sadoughi University of Medical Sciences and Health Services: Shahid Sadoughi University of Medical Sciences and Health Services

\section{Abbas Ali Sangouni}

Shahid Sadoughi University of Medical Sciences and Health Services: Shahid Sadoughi University of Medical Sciences and Health Services

\section{Zohreh Sadat Sangsefidi}

Shahid Sadoughi University of Medical Sciences and Health Services: Shahid Sadoughi University of Medical Sciences and Health Services

\section{Mahdieh Hosseinzadeh}

Shahid Sadoughi University of Medical Sciences and Health Services: Shahid Sadoughi University of Medical Sciences and Health Services

\section{Mohsen Akhondi-Meybodi}

Shahid Sadoughi University of Medical Sciences and Health Services: Shahid Sadoughi University of Medical Sciences and Health Services

\section{Alimohammad Ranjbar}

Shahid Sadoughi University of Medical Sciences and Health Services: Shahid Sadoughi University of Medical Sciences and Health Services

\section{Hossein Fallahzadeh}

Shahid Sadoughi University of Medical Sciences and Health Services: Shahid Sadoughi University of Medical Sciences and Health Services

\section{Hassan Mozaffari-Khosravi (D mozaffari.kh@gmail.com )}

Shahid Sadoughi University of Medical Sciences and Health Services: Shahid Sadoughi University of Medical Sciences and Health Services

\section{Research}

Keywords: Non-alcoholic fatty liver disease, Cornus mas L., Blood pressure, Obesity 
DOI: https://doi.org/10.21203/rs.3.rs-1167200/v1

License: (c) (1) This work is licensed under a Creative Commons Attribution 4.0 International License. Read Full License 


\section{Abstract}

Background:

Obesity is an important factor in the pathogenesis of non-alcoholic fatty liver disease (NAFLD). Patients with NAFLD are at increased risk for hypertension. Some investigations have hypothesized that Cornus mas $L$. fruit can improve blood pressure and obesity. We investigated the effect of Cornus mas $L$. fruit extract on blood pressure variables, anthropometric and body composition indices in patients with NAFLD.

Methods:

This double-blind, randomized controlled trial was conducted on fifty patients with NAFLD. Patients received $20 \mathrm{cc} / \mathrm{d}$ Cornus mas $L$. fruit extract or placebo for 12 weeks. We measured diastolic blood pressure (DBP), systolic blood pressure (SBP), weight, waist circumference (WC), hip circumference (HC), waist-to-hip ratio (WHR), body fat mass (BFM), body fat percent (BFP) and fat free mass (FFM) at the baseline and after intervention.

Results:

The treatment group compared to the control group showed a significant reduction in DBP $(-8.62 \pm 11.86$ vs. $0.53 \pm 8.53 ; P=0.009)$, $\operatorname{SBP}(-8.63 \pm 14.37$ vs. $0.0 \pm 12.67 ; P=0.04), B F M(-0.2 \pm 3.9$ vs. $0.7 \pm 2.4 ; P=$ $0.02)$ and $B F P(-0.2 \pm 4.9$ vs. $0.8 \pm 2.8 ; P=0.05)$ after adjusting for confounding factors. However, we found no significant difference between groups in weight, WC, HC, WHR and FFM $(P>0.05)$.

Conclusions:

Cornus mas L. can improve blood pressure. Further studies with higher dosages of extract are needed to clarify its effects on obesity. Trial registration: Registered on 30 September 2018 at Iranian Registry of Clinical Trials IRCT20180419039359N1 (https://www.irct.ir/trial/30707).

\section{Introduction}

Non-alcoholic fatty liver disease (NAFLD) is known as the accumulation of fat (mainly triglyceride) in the liver (more than $5 \%$ of liver weight) without evidence of alcohol consumption $(1,2)$. The prevalence of NAFLD is high in both developed and developing countries (3-5). It is the most common chronic liver disease worldwide and the main cause of liver transplantation $(6,7)$. Obesity, disrupted lipid metabolism, inflammation and insulin resistance are the most important factors that contribute to the development and progression of NAFLD (8-10). A strong association between NAFLD with both metabolic syndrome and cardiovascular disease (CVD) has been confirmed $(11,12)$. In addition, patients suffering from NAFLD compared to the healthy subjects are at higher risk for hypertension $(13,14)$. Modifiable lifestyle factors such as weight loss and adherence to the healthy plant-based dietary patterns are the important strategies to manage NAFLD (15-17). 
Cornus mas $L$. (cornelian cherry) fruit is a rich source of compounds with anti-inflammatory and antioxidant properties such as anthocyanins, flavonoids and polyphenols (18-20). It has been reported that Cornus mas L. fruit/anthocyanins can improve obesity and hypertension through several mechanisms (21-24). The effects of Cornus mas $L$. fruit on some factors involved in the pathogenesis of NAFLD such as insulin resistance, dyslipidemia and inflammation have been examined (25-27). A few number of studies have examined the effect of Cornus mas $L$. on anthropometric and body composition indices $(25,26)$. The studies that investigated the effect of Cornus mas $L$. fruit in patients with NAFLD are rare (28). To the best of our knowledge, there is no study evaluating the effect of Cornus mas $L$. fruit on anthropometric and body composition indices in patients with NAFLD. In addition, there was no clinical trial that investigated the effect of Cornus mas $L$. fruit on blood pressure. Accordingly, we designed a clinical trial to examine the effect of Cornus mas $L$. fruit extract blood pressure variables, anthropometric and body composition indices in patients with NAFLD.

\section{Methods}

Recruitment and eligibility screening

We recruited the subjects from gastroenterology clinics affiliated with Diabetes Research Center of Shahid Sadoughi University of Medical Sciences, Yazd, Iran, between May 2019 to August 2019. A total of 50 subjects met the inclusion criteria including age 25-65 years, diagnosis of NAFLD by ultrasonography, alanine aminotransferase (ALT) serum concentrations $\geq 30 \mathrm{U} / \mathrm{L}$ in men and $\geq 19 \mathrm{U} / \mathrm{L}$ in women (29-31), and resident of Yazd city. The exclusion criteria included history of alcohol abuse, viral hepatitis, liver cancer, Wilson, type 2 diabetes mellitus (T2DM), mental diseases, pregnancy, lactation, taking corticosteroids, non-steroidal anti-inflammatory drugs, hypoglycemic drugs, tamoxifen, sodium valproate, methotrexate, amiodarone, anti-retroviral agents for HIV, probiotics, antioxidant and antiinflammatory supplements such as vitamin D, vitamin E, omega-3 and resveratrol, poor compliance and unwillingness to continue the study.

Trial design

We designed a double-blind randomized, placebo-controlled clinical trial (RCT) evaluating the effect of Cornus mas $L$. fruit extract intake for 12 weeks on blood pressure, anthropometric and body composition indices in patients with NAFLD. at the beginning, the participants signed a written informed consent that was confirmed by the ethical committee of Shahid Sadoughi University of Medical Sciences and Health Services in Yazd (IR.SSU.SPH.REC.1399.019). We registered the protocol at the Iranian clinical trials website (http://www.irct.ir) under code number IRCT20180419039359N1 (https://www.irct.ir/trial/30707). We stratified the participants according to their age (25-45; 45-65 years) and gender (male/female) and the participants were divided into the treatment group $(n=25)$ and the control group $(n=25)$ by a person who did not contribute to the study. To perform randomization, we used random number table that was produced by random allocation software (32). The patients and investigators were blinded until the end of the trial. 
We provided the Cornus mas $L$. fresh fruits from the forests of Ghazvin, Iran. Preparation of the Cornus mas $L$. fruit extract and placebo was performed in the Pharmacy Faculty of Shahid Sadoughi University of Medical Sciences. In addition, to determine total anthocyanins content of final extract we used pH differential method (33). We reported the details of Cornus mas $L$. fruit extract preparation as well as total anthocyanins content determination in our previous article (28).

Intervention

Based on previous clinical trials $(25,27)$, we considered $20 \mathrm{cc} / \mathrm{d}$ Cornus mas $L$. fruit extract as the optimal dosage for treatment group. This amount provided $32 \mathrm{mg} / \mathrm{d}$ total anthocyanin. $20 \mathrm{cc}$ liquid extract was equivalent to $2800 \mathrm{mg}$ dried extract. The safety of this dosage was confirmed by previous studies $(25,26,34,35)$. The control group received $20 \mathrm{cc} / \mathrm{d}$ placebo without any anthocyanin. The Cornus mas $L$. fruit extract and the placebo that had similar appearance were packed in bottles with the same color, shape and size. The participants received the bottles every 2 weeks. We assessed the rate of compliance every 2 weeks based on extract consumption. Consumption of extracts less than $80 \%$ of the prescribed amount was considered as poor compliance. Adverse events during follow-up were checked every 2 weeks.

Dietary intake and physical activity assessment

We evaluated the dietary intake of participants at the baseline and after intervention utilizing a 3-day (1 weekend day and 2 nonconsecutive weekdays) food record. Energy and macronutrients intakes were calculated using nutritionist IV software (version 7.0; N-Squared Computing, Salem, OR, USA) (36). In addition, we used a short form of International physical activity questionnaire (IPAQ) $(37,38)$ to assess physical activity at the baseline and after intervention.

Blood pressure measurement

We measured diastolic blood pressure (DBP) and systolic blood pressure (SBP) under the standard protocol at the baseline and after intervention, in the nondominant arm after $10 \mathrm{~min}$ of rest. Measurements were performed by a trained person using a mercury sphygmomanometer device (MicrolifeBP AG1-10).

Anthropometric and body composition evaluations

Measuring height, weight, waist circumference (WC), hip circumference (HC), waist-to-hip ratio (WHR), body fat mass (BFM), body fat percent (BFP) and fat free mass (FFM) was performed at the baseline and after intervention by stadiometer, scale, and bioelectrical impedance analyzer (BIA) (In Body 770, Korea) based on the standard instructions.

\section{Statistical analysis}


We calculated the sample size ( 25 per group) based on fibrosis score, with $95 \%$ confidence interval, $a=$ 0.05 , power $=80 \%$ in our previous article (28). We performed the power analysis, and power $=80 \%$ was estimated. Kolmogorov-Smirnov test was utilized to evaluate the parameters distribution. We used independent t-test and chi-square test for continuous and categorical variables, respectively to compare differences between groups. Independent t-test was utilized to compare the means of variables at the end of the study, as well as the mean changes between groups. Parameters with abnormal distribution were compared between groups utilizing Mann-Whitney $\mathrm{U}$ test. In addition, we used paired t-test (for parameters with normal distribution), and Wilcoxon test (for parameters with abnormal distribution) to perform within group comparisons. Univariate ANCOVA was used to control confounding factors. The primary outcomes were reported based on intention-to-treat (ITT) approach. Statistical package for social science (SPSS) software (Chicago, Illinois, USA) version 24 was utilized for statistical analyses.

\section{Results}

Characteristics and anthropometric variables

A total of 40 patients completed the study. Ten patients were excluded from the trial for reasons such as flatulence $(n=1)$, immigration $(n=2)$, unwillingness to continue the study $(n=3)$, surgery $(n=1)$, and corona virus pandemic $(n=3)$ (Figure 1). There was no difference between the treatment group and the control groups in the baseline variables (Table 1). In addition, we found no difference between the treatment group and the control groups in dietary intakes and physical activity at the baseline and after intervention (Table 2). The patients reported no serious adverse event related to extracts during follow-up. One patient with history of gastrointestinal disorders, had flatulence during intervention, and was excluded. 
Table 1

Baseline characteristics of patients with NAFLD

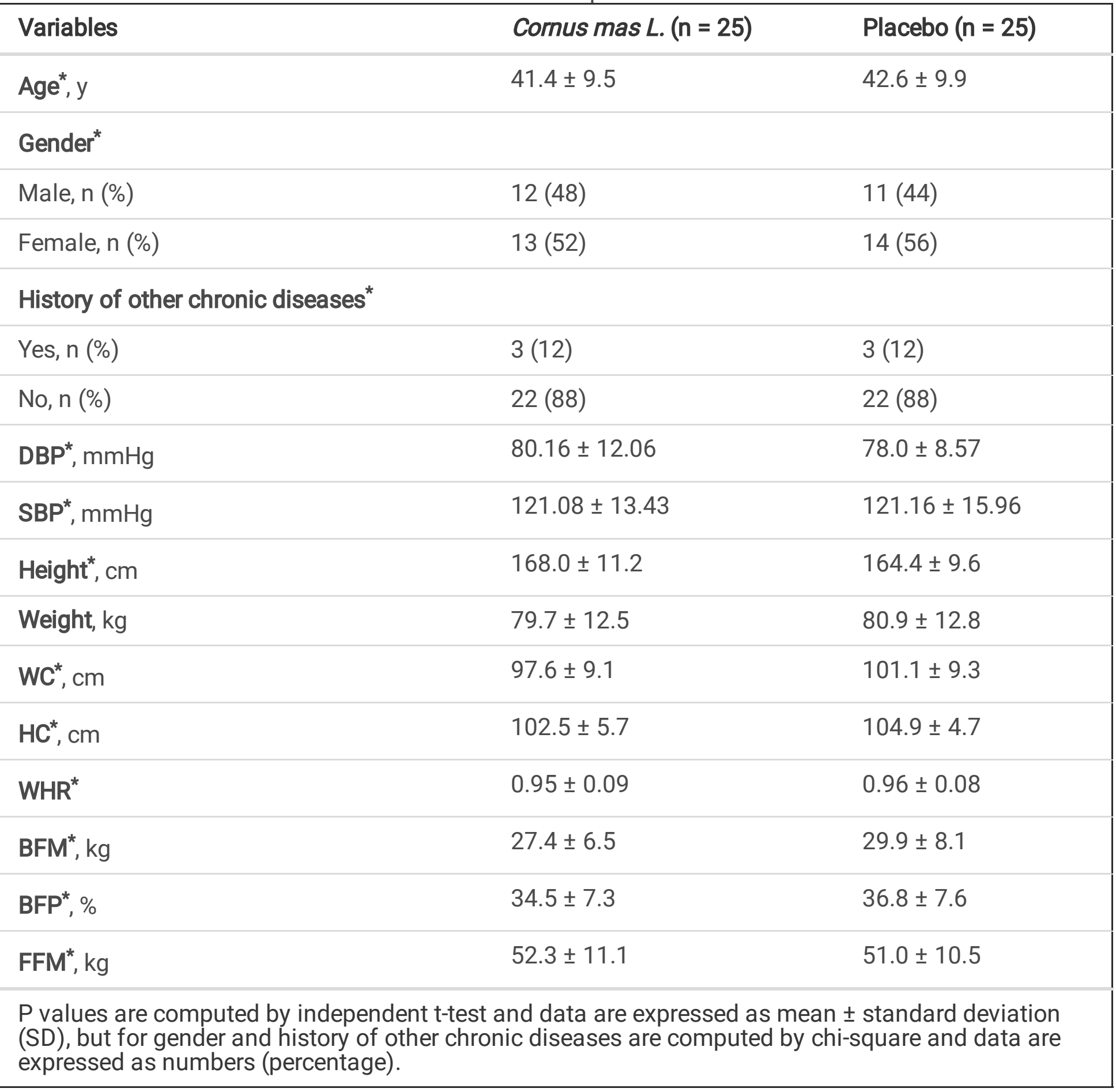


Table 2

Dietary intakes and physical activity in patients with NAFLD

\begin{tabular}{llll} 
variables & Cornus mas $L .(n=25)$ & Placebo $(\mathbf{n = 2 5 )}$ & $P^{\dagger}$ \\
\hline \multicolumn{2}{l}{ Energy intake, $\mathrm{kcal} / \mathrm{d}$} & & 0.11 \\
Baseline & $2960.80 \pm 885.15$ & $2576.24 \pm 617.81$ & 0.16 \\
Week 12 & $2943.50 \pm 758.81$ & $2635.78 \pm 621.91$ & \\
$P$ & 0.85 & 0.31 &
\end{tabular}

Carbohydrates, $\mathrm{g} / \mathrm{d}$

\begin{tabular}{llll} 
Baseline & $425.08 \pm 185.33$ & $375.33 \pm 128.80$ & 0.32 \\
Week 12 & $460.46 \pm 172.58$ & $379.39 \pm 132.36$ & 0.10 \\
\hline P & 0.32 & 0.80 &
\end{tabular}

Proteins, $\mathrm{g} / \mathrm{d}$

\begin{tabular}{llll} 
Baseline & $95.25(83.30$ to 120.22$)$ & $88.36(67.44$ to 99.17$)$ & $0.14^{*}$ \\
\hline Week 12 & $93.99(81.58$ to 134.23$)$ & $96.34(74.94$ to 113.18$)$ & $0.48^{*}$ \\
\hline P & $0.83^{* *}$ & $0.19^{* \star}$ &
\end{tabular}

Fats, $\mathrm{g} / \mathrm{d}$

\begin{tabular}{llll} 
Baseline & $93.18(54.68$ to 156.09$)$ & $69.37(53.85$ to 106.85$)$ & $0.23^{*}$ \\
\hline Week 12 & $83.46(59.56$ to 99.97$)$ & $72.12(61.25$ to 100.25$)$ & $0.76^{*}$ \\
\hline$P$ & $0.30^{\star *}$ & $0.45^{\star *}$ &
\end{tabular}

Physical activity, (MET/hr/week)

\begin{tabular}{llll} 
Baseline & $660.45(307.12$ to 791.25$)$ & $341.5(0$ to 1705.50$)$ & $0.75^{\star}$ \\
\hline Week 12 & $850.50(111.37$ to 881.29$)$ & $283.75(0$ to 1234.12$)$ & $0.49^{\star}$ \\
\hline P & $0.31^{\star *}$ & $0.28^{\star *}$ &
\end{tabular}

Values of total energy and carbohydrates are presented as mean \pm standard deviation (SD), while for proteins, fats and physical activity are presented as median and quartile range.

\section{Outcomes}

At the baseline, there was no significant difference between the treatment and the control groups in terms of DBP $(P=0.46)$ and SBP $(P=0.98)$ (Table 3). After intervention, a significant difference between two groups was observed in DBP $(P=0.01)$, but, SBP remained without significant difference $(P=0.07)$. The treatment group compared to the control group showed a significant reduction in DBP $(-8.62 \pm 11.86$ vs. 
$0.53 \pm 8.53 ; P=0.009)$, and SBP $(-8.63 \pm 14.37$ vs. $0.0 \pm 12.67 ; P=0.04)$ after adjusting for confounding variables (Table 3 ).

Table 3

Effect of Cornus mas L. fruit extract on blood pressure in patients with NAFLD*

\begin{tabular}{|c|c|c|c|c|}
\hline Indices & Cornus mas $L .(n=25)$ & Placebo $(n=25)$ & $P^{\dagger}$ & $P^{t+}$ \\
\hline $\mathrm{DBP}(\mathrm{mmHg})$ & & & & 0.000 \\
\hline Baseline & $80.16 \pm 12.06$ & $78.0 \pm 8.57$ & 0.46 & \\
\hline Week 12 & $71.54 \pm 7.82$ & $78.53 \pm 10.67$ & 0.01 & \\
\hline$P$ & 0.001 & 0.75 & & \\
\hline Mean change of DBP & $-8.62 \pm 11.86$ & $0.53 \pm 8.53$ & 0.003 & \\
\hline $\mathrm{SBP}(\mathrm{mmHg})$ & & & & 0.04 \\
\hline Baseline & $121.08 \pm 13.43$ & $121.16 \pm 15.96$ & 0.98 & \\
\hline Week 12 & $112.45 \pm 16.63$ & $121.16 \pm 16.87$ & 0.07 & \\
\hline$P$ & 0.006 & 0.99 & & \\
\hline Mean change of SBP & $-8.63 \pm 14.37$ & $0.0 \pm 12.67$ & 0.02 & \\
\hline
\end{tabular}

In addition, there was no significant difference between the two groups in weight $(P=0.73)$, WC $(P=$ 0.18), HC ( $P=0.10)$, WHR $(P=0.71), B F M(P=0.25), B F P(P=0.29)$ and FFM $(P=0.67)$ at the baseline (Table 4). In addition, we found no significant difference between two groups in weight $(P=0.73)$, WC ( $P$ $=0.20)$, WHR $(P=0.82), B F M(P=0.14), B F P(P=0.14)$ and FFM $(P=0.49)$ after intervention; but, level of $\mathrm{HC}(\mathrm{P}=0.03)$ was significantly higher in the control group compared to the treatment group (Table 4).

After adjusting for confounding factors, there was a significant difference between the treatment and the control groups in the mean change of BFM (-0.2 \pm 3.9 vs. $0.7 \pm 2.4 ; \mathrm{P}=0.02)$ and BFP $(-0.2 \pm 4.9$ vs. $0.8 \pm$ 2.8; $P=0.05)$; however, we found no significant difference between two groups in mean change of weight $(0.5 \pm 2.3$ vs. $0.5 \pm 1.5 ; P=0.06)$, WC $(0.8 \pm 3.3$ vs. $1.0 \pm 2.7 ; P=0.74), \mathrm{HC}(0.1 \pm 1.3$ vs. $0.9 \pm 2.5 ; \mathrm{P}=$ $0.10)$, WHR $(0.01 \pm 0.03$ vs. $0.00 \pm 0.03 ; P=0.51)$ and FFM $(0.7 \pm 3.7$ vs. $-0.2 \pm 2.4 ; P=0.40)($ Table 4$)$. 
Table 4

Effect of Cornus mas L. fruit extract on body composition in patients with NAFLD*

\begin{tabular}{|c|c|c|c|c|}
\hline Indices & Cornus mas L. $(n=25)$ & Placebo $(n=25)$ & $P^{\dagger}$ & $P^{t+t}$ \\
\hline Weight (kg) & & & & 0.06 \\
\hline Baseline & $79.7 \pm 12.5$ & $80.9 \pm 12.8$ & 0.73 & \\
\hline Week 12 & $80.2 \pm 12.5$ & $81.4 \pm 13.0$ & 0.73 & \\
\hline$P$ & 0.32 & 0.13 & & \\
\hline Mean change of weight & $0.5 \pm 2.3$ & $0.5 \pm 1.5$ & 0.99 & \\
\hline WC $(\mathrm{cm})$ & & & & 0.74 \\
\hline Baseline & $97.6 \pm 9.1$ & $101.1 \pm 9.3$ & 0.18 & \\
\hline Week 12 & $98.4 \pm 10.2$ & $102.1 \pm 10.5$ & 0.20 & \\
\hline$P$ & 0.29 & 0.08 & & \\
\hline Mean change of WC & $0.8 \pm 3.3$ & $1.0 \pm 2.7$ & 0.74 & \\
\hline $\mathrm{HC}(\mathrm{cm})$ & & & & 0.10 \\
\hline Baseline & $102.5 \pm 5.7$ & $104.9 \pm 4.7$ & 0.10 & \\
\hline Week 12 & $102.6 \pm 5.3$ & $105.8 \pm 4.9$ & 0.03 & \\
\hline$P$ & 0.54 & 0.11 & & \\
\hline Mean change of $\mathrm{HC}$ & $0.1 \pm 1.3$ & $0.9 \pm 2.5$ & 0.24 & \\
\hline WHR & & & & 0.51 \\
\hline Baseline & $0.95 \pm 0.09$ & $0.96 \pm 0.08$ & 0.71 & \\
\hline Week 12 & $0.96 \pm 0.10$ & $0.96 \pm 0.09$ & 0.82 & \\
\hline$P$ & 0.44 & 0.82 & & \\
\hline Mean change of WHR & $0.01 \pm 0.03$ & $0.00 \pm 0.03$ & 0.73 & \\
\hline BFM $(k g)$ & & & & 0.02 \\
\hline Baseline & $27.4 \pm 6.5$ & $29.9 \pm 8.1$ & 0.25 & \\
\hline Week 12 & $27.2 \pm 6.9$ & $30.6 \pm 8.3$ & 0.14 & \\
\hline$P$ & 0.94 & 0.10 & & \\
\hline Mean change of BFM & $-0.2 \pm 3.9$ & $0.7 \pm 2.4$ & 0.36 & \\
\hline
\end{tabular}

Values are presented as mean \pm standard deviation (SD). 


\begin{tabular}{|c|c|c|c|c|}
\hline Indices & Cornus mas $L .(n=25)$ & Placebo $(n=25)$ & $P^{\dagger}$ & $P^{+t}$ \\
\hline BFP (\%) & & & & 0.05 \\
\hline Baseline & $34.5 \pm 7.3$ & $36.8 \pm 7.6$ & 0.29 & \\
\hline Week 12 & $34.3 \pm 7.6$ & $37.6 \pm 7.8$ & 0.14 & \\
\hline $\mathrm{P}$ & 0.82 & 0.16 & & \\
\hline Mean change of BFP & $-0.2 \pm 4.9$ & $0.8 \pm 2.8$ & 0.37 & \\
\hline FFM $(\mathrm{kg})$ & & & & 0.40 \\
\hline Baseline & $52.3 \pm 11.1$ & $51.0 \pm 10.5$ & 0.67 & \\
\hline Week 12 & $53.0 \pm 11.7$ & $50.8 \pm 10.4$ & 0.49 & \\
\hline$P$ & 0.30 & 0.82 & & \\
\hline Mean change of FFM & $0.7 \pm 3.7$ & $-0.2 \pm 2.4$ & 0.32 & \\
\hline
\end{tabular}

\section{Discussion}

Based on our knowledge, our study was the first study that examined the effect of Cornus mas $L$. fruit extract on blood pressure variable, anthropometric and body composition indices in patients with NAFLD. Cornus mas $L$. fruit extract $(20 \mathrm{cc} / \mathrm{d})$ for 12 weeks could improve blood pressure, BFM and BFP. However, weight, WC, HC, WHR and FFM remained without significant change.

Cornus mas $L$. fruit and its biological compounds through various mechanisms and pathways such as inducing endothelial nitric oxide gene expression, regulating nitric oxide synthase and increasing endogenous production of nitric oxide, modulating nuclear factor- $\mathrm{K}$ B (NF-KB) and mitogen-activated protein kinase (MAPK) signaling pathways, reducing pro-inflammatory cytokines, decreasing peroxynitrate and reactive oxygen species (ROS) levels, and attenuating vasoconstriction by regulating angiotensin-converting enzyme (ACE) and angiotensin II receptor activity can improve hypertension (22, 39-42). There is no study investigating the effect of Cornus mas $L$. fruit on blood pressure in subjects in NAFLD. Johnson et al. (43) reported that daily consumption of blueberry, a rich source of anthocyanins, for 8 weeks in postmenopausal women with pre- and stage 1-hypertension can reduce DBP and SBP. In addition, the study of Broncel et al. (44) found that intake of $300 \mathrm{mg} / \mathrm{d}$ Aronia melanocarpa extract (another rich source of anthocyanins) for 2 months reduces DBP and SBP in subjects with metabolic syndrome. Moreover, the study conducted by Basu et al. (45) suggested that freeze-dried blueberry beverage ( $50 \mathrm{~g}$ freeze-dried blueberries) daily for 8 weeks can reduced DBP and SBP in participants with metabolic syndrome. However, a clinical study conducted by Hassellund et al. (46) demonstrated that anthocyanins supplementation (320 mg twice per day) after 4 weeks did not reduce blood pressure variables in subjects with hypertension. A meta-analysis found that anthocyanins supplementation has 
no effect on DBP and SBP (47). Health status of participants, duration of follow-up, type of supplement and dosage of supplement are the most important differences between these studies. It seems, difference in type of supplements is the main factor explaining discrepancies between findings of mentioned studies. In general, anthocyanins supplementation did not show promising results in this field, while receiving sources of anthocyanins reported the beneficial effects on blood pressure. We used Cornus mas $L$. fruit extract containing several biological compounds that probably have synergistic effects.

On the other hand, the evidence suggested that Cornus mas $L$. fruit and its main compounds by inhibiting hepatic lipogenesis, increasing hepatic lipid oxidation and clearance, regulating the expression of peroxisome proliferator-activated receptors (PPARs), increasing the activity of AMP-activated protein kinase (AMPK) pathway in the white adipose tissue, decreasing adiponectin levels and activating adiponectin signaling, decreasing levels of adipocytokines, reducing the activity of pancreatic lipase and absorption of lipids can reduce obesity $(21,48-52)$. We found no similar study investigating the effect of Cornus mas $L$. fruit on obesity in patients with NAFLD. Gholamrezayi et al. (26) have examined the effect of 8-week Cornus mas L. fruit extract intake $(900 \mathrm{mg} / \mathrm{d})$ on anthropometric variables of postmenopausal women, and found a significant decrease in weight and WC. The dosage of Cornus mas $L$. fruit extract in the mentioned study was higher than our study. However, the study of Asgary et al. (25) showed no beneficial effect of Cornus mas $L$. fruit $(100 \mathrm{~g} / \mathrm{d})$ for 6 weeks in dyslipidemic children and adolescents. Some studies have examined the effect of other rich sources of anthocyanins on body composition. It has been reported that 12-week cranberry extract intake $(1500 \mathrm{mg} / \mathrm{d})$ did not change the mean of WC in subjects with T2DM (53). Likewise, Basu et al. (45) did not find the beneficial effect of blueberry intake on weight and WC among subjects suffering from metabolic syndrome. The pilot trial of Zhang et al. (54) reported that purified anthocyanins supplementation $(320 \mathrm{mg} / \mathrm{d})$ derived from bilberry and black currant for 12 weeks has no effect on weight, WC, HC and WHR in patients with NAFLD. It seems, dosage and type of extract are important in this field, and probably higher dosages of Cornus mas $L$. fruit extract can improve the indicators of obesity.

To comply with principals of ethics in research, we declare that our research group reported the findings of liver function (28). We used the same data for the present article, and figure 1, sample size information, some baseline characteristics, dietary intakes and physical activity of our previous article were added to the present article.

The present study had some important advantages. This was the first RCT that examined the effect of Cornus mas $L$. fruit extract on blood pressure variables and body composition indices in patients with NAFLD. In addition, the extract was standardized according to total anthocyanin content. Similar to other RCTs, this study had some limitations. Liver ultrasonography was used for diagnosis of NAFLD, while Fibroscan has higher accuracy than ultrasonography $(55,56)$. As another important limitation, we did not measure the serum levels of anthocyanins to evaluate the bioavailability of anthocyanins.

\section{Conclusion}


Overall, 12-week Cornus mas L. fruit extract intake $(20 \mathrm{cc} / \mathrm{d})$ could improve blood pressure and body fat. However, further studies utilizing higher dosages of Cornus mas $L$. fruit extract are required to clarify the real effects of Cornus mas $L$. fruit extract on obesity.

\section{Abbreviations}

ACE

angiotensin-converting enzyme

AMPK

adenosine monophosphate activated protein kinase

ALT

alanine aminotransferase

BFM

body fat mass

BFP

body fat percent

CVD

cardiovascular disease

DBP

diastolic blood pressure

FFM

fat free mass

FPG

fasting plasma glucose

$\mathrm{HC}$

hip circumference

ITT

intention-to-treat

IPAQ

international physical activity questionnaire

MAPK

mitogen-activated protein kinase

MET-h

metabolic equivalent task hours

NAFLD

nonalcoholic fatty liver disease

NF-KB

nuclear factor-K $B$

PPARs

peroxisome proliferator-activated receptors 
RCT

randomized controlled trial

ROS

reactive oxygen species

SBP

systolic blood pressure

SPSS

statistical package for social science

T2DM

type 2 diabetes mellitus

WC

waist circumference

WHR

waist-to-hip ratio.

\section{Declarations}

\section{Ethics approval and consent to participate}

The research council of Nutrition and Food Security Research Center, Shahid Sadoughi University of Medical Sciences and Health Services approved the study protocol. The methods were performed in accordance with the Helsinki Declaration. The ethical committee of Shahid Sadoughi University of Medical Sciences and Health Services in Yazd approved the written informed consent (code number: IR.SSU.SPH.REC.1399.019). The written informed consent was obtained from all participants before the data collection.

\section{Consent for publication}

Not applicable.

\section{Availability of data and materials}

The data and materials of the current study is available from the corresponding author on reasonable request.

\section{Competing interests}

The authors have declared no competing interests. 


\section{Funding}

Shahid Sadoughi University of Medical Sciences and Health Services, Yazd, Iran supported this study. This was a financial support for student thesis process including laboratory works, and providing kits.

\section{Authors' contributions}

H.M-Kh, M.H, F.Y and Z.S: conducted the study; H.M-Kh, M.A-M and A.R: provided material and technical support, H.F, A.S and F.Y: carried out the statistical analysis, and interpreted the finding; A.S: drafted the manuscript; H.M-Kh: critically revised the manuscript; and H.M-Kh: supervised the study. All authors reviewed the manuscript.

\section{Acknowledgments}

We acknowledge the contribution of all participants and investigators.

\section{Authors' information}

${ }^{1}$ Department of Nutrition, School of Public Health, Shahid Sadoughi University of Medical Sciences, Yazd, Iran. ${ }^{2}$ Nutrition and Food Security Research Center, School of Public Health, Shahid Sadoughi University of Medical Sciences, Yazd, Iran. ${ }^{3}$ Gastroentrology Department, Shahid Sadoughi Hospital, Faculty of Medicine, Shahid Sadoughi University of Medical Sciences, Yazd, Iran. ${ }^{4}$ Department of Pharmacognosy, Faculty of Pharmacy, Shahid Sadoughi University of Medical Sciences, Yazd, Iran. ${ }^{5}$ Herbal Medicine Center, Faculty of Pharmacy, Shahid Sadoughi University of Medical Sciences, Yazd, Iran. ${ }^{6}$ Research Center of Prevention and Epidemiology of Non-Communicable Disease, Department of Biostatistics and Epidemiology, School of Public Health, Shahid Sadoughi University of Medical Sciences, Yazd, Iran.

\section{References}

1. Chalasani N, Younossi Z, Lavine JE, Diehl AM, Brunt EM, Cusi K, et al. The diagnosis and management of non-alcoholic fatty liver disease: Practice Guideline by the American Association for the Study of Liver Diseases, American College of Gastroenterology, and the American Gastroenterological Association. Hepatology. 2012;55(6):2005-23.

2. Carr RM, Oranu A, Khungar V. Nonalcoholic Fatty Liver Disease: Pathophysiology and Management. Gastroenterol Clin North Am. 2016;45(4):639-652.

3. Araújo AR, Rosso N, Bedogni G, Tiribelli C, Bellentani S. Global epidemiology of non-alcoholic fatty liver disease/non-alcoholic steatohepatitis: What we need in the future. Liver Int. 2018;38 Suppl $1: 47-51$. 
4. Moghaddasifar I, Lankarani KB, Moosazadeh M, Afshari M, Ghaemi A, Aliramezany M, et al. Prevalence of non-alcoholic fatty liver disease and its related factors in Iran. Int J Organ Transplant Med. 2016;7(3):149-160.

5. Younossi Z, Anstee QM, Marietti M, Hardy T, Henry L, Eslam M, et al. Global burden of NAFLD and NASH: Trends, predictions, risk factors and prevention. Nat Rev Gastroenterol Hepatol. 2018;15(1):11-20.

6. Wong RJ, Aguilar M, Cheung R, Perumpail RB, Harrison SA, Younossi ZM, et al. Nonalcoholic steatohepatitis is the second leading etiology of liver disease among adults awaiting liver transplantation in the United States. Gastroenterology. 2015;148(3):547-55.

7. Rinella ME. Nonalcoholic fatty liver disease a systematic review. JAMA. 2015;313(22):2263-73.

8. Berlanga A, Guiu-Jurado E, Porras JA, Auguet T. Molecular pathways in non-alcoholic fatty liver disease. Clin Exp Gastroenterol. 2014;7:221-39.

9. Sangouni AA, Ghavamzadeh S, Jamalzehi A. A narrative review on effects of vitamin $D$ on main risk factors and severity of Non-Alcoholic Fatty Liver Disease. Diabetes Metab Syndr Clin Res Rev. 2019;13(3):2260-5.

10. Sangouni AA, Ghavamzadeh S. A review of synbiotic efficacy in non-alcoholic fatty liver disease as a therapeutic approach. Diabetes Metab Syndr Clin Res Rev. 2019;13(5):2917-2922.

11. Kim $\mathrm{CH}$, Younossi ZM. Nonalcoholic fatty liver disease: A manifestation of the metabolic syndrome. Cleve Clin J Med. 2008;75(10):721-8.

12. Liu H, Lu HY. Nonalcoholic fatty liver disease and cardiovascular disease. World J Gastroenterol. 2014;20(26):8407-15.

13. Hagström H, Nasr P, Ekstedt M, Hammar U, Stål P, Askling J, et al. Cardiovascular risk factors in nonalcoholic fatty liver disease. Liver Int. 2019;39(1):197-204.

14. Oikonomou D, Georgiopoulos G, Katsi V, Kourek C, Tsioufis C, Alexopoulou A, et al. Non-alcoholic fatty liver disease and hypertension: Coprevalent or correlated? Eur J Gastroenterol Hepatol. 2018;30(9):979-85.

15. Sangouni AA, Hassani Zadeh S, Mozaffari-Khosravi H, Hosseinzadeh M. Effect of Mediterranean diet on liver enzymes: A systematic review and meta-analysis of randomized controlled trials. Br $\mathrm{J}$ Nutr. 2021;1-9. doi:10.1017/S0007114521002270.

16. Tomasiewicz K, Flisiak R, Halota W, Jaroszewicz J, Lebensztejn D, Lisik W, et al. Recommendations for the management of non-alcoholic fatty liver disease (NAFLD). Clin Exp Hepatol. 2018;4(3):153-7.

17. Zelber-Sagi S, Godos J, Salomone F. Lifestyle changes for the treatment of nonalcoholic fatty liver disease: A review of observational studies and intervention trials. Therap Adv Gastroenterol. 2016;9(3):392-407.

18. Ga冈stoł M, Krośniak M, Derwisz M, Dobrowolska-Iwanek J. Cornelian cherry (Cornus mas L.) juice as a potential source of biological compounds. J Med Food. 2013;16(8):728-32. 
19. Dinda B, Kyriakopoulos AM, Dinda S, Zoumpourlis V, Thomaidis NS, Velegraki A, et al. Cornus mas L. (cornelian cherry), an important European and Asian traditional food and medicine: Ethnomedicine, phytochemistry and pharmacology for its commercial utilization in drug industry. J Ethnopharmacol. 2016;193:670-90.

20. Szczepaniak OM, Kobus-Cisowska J, Kusek W, Przeor M. Functional properties of Cornelian cherry (Cornus mas L.): a comprehensive review. Eur Food Res Technol. 2019;245(10):2071-87.

21. Naseri R, Farzaei F, Haratipour P, Nabavi SF, Habtemariam S, Farzaei MH, et al. Anthocyanins in the Management of Metabolic Syndrome: A Pharmacological and Biopharmaceutical Review. Front Pharmacol. 2018;9:1310.

22. Hügel HM, Jackson N, May B, Zhang AL, Xue CC. Polyphenol protection and treatment of hypertension. Phytomedicine. 2016;23(2):220-31.

23. Jayaprakasam B, Olson LK, Schutzki RE, Tai MH, Nair MG. Amelioration of obesity and glucose intolerance in high-fat-fed C57BL/ 6 mice by anthocyanins and ursolic acid in cornelian cherry (Cornus mas). J Agric Food Chem. 2006;54(1):243-8.

24. Guo H, Xia M, Zou T, Ling W, Zhong R, Zhang W. Cyanidin 3-glucoside attenuates obesity-associated insulin resistance and hepatic steatosis in high-fat diet-fed and $\mathrm{db} / \mathrm{db}$ mice via the transcription factor Fox01. J Nutr Biochem. 2012;23(4):349-60.

25. Asgary S, Kelishadi R, Rafieian-Kopaei M, Najafi S, Najafi M, Sahebkar A. Investigation of the lipidmodifying and antiinflammatory effects of cornus mas L. supplementation on dyslipidemic children and adolescents. Pediatr Cardiol. 2013;34(7):1729-35.

26. Gholamrezayi A, Aryaeian N, Rimaz S, Abolghasemi J, Fallah S, Moradi N, et al. The effect of Cornus mas fruit extract consumption on lipid profile, glycemic indices, and leptin in postmenopausal women- A randomized clinical trial. Phyther Res. 2019;33(11):2979-88.

27. Soltani R, Gorji A, Asgary S, Sarrafzadegan N, Siavash M. Evaluation of the Effects of Cornus mas L. Fruit Extract on Glycemic Control and Insulin Level in Type 2 Diabetic Adult Patients: A Randomized Double-Blind Placebo-Controlled Clinical Trial. Evidence-based Complement Altern Med. 2015;2015:740954.

28. Sangsefidi ZS, Yarhosseini F, Hosseinzadeh M, Ranjbar A, Akhondi-Meybodi M, Fallahzadeh $\mathrm{H}$, et al. The effect of (Cornus mas L.) fruit extract on liver function among patients with nonalcoholic fatty liver: A double-blind randomized clinical trial. Phyther Res. 2021;35(9):5259-5268.

29. Tomizawa M, Kawanabe Y, Shinozaki F, Sato S, Motoyoshi Y, Sugiyama T, et al. Elevated levels of alanine transaminase and triglycerides within normal limits are associated with fatty liver. Exp Ther Med. 2014;8(3):759-62.

30. Prati D, Taioli E, Zanella A, Della Torre E, Butelli S, Del Vecchio E, et al. Updated definitions of healthy ranges for serum alanine aminotransferase levels. Ann Intern Med. 2002;137(1):1-9.

31. Poustchi H, George J, Esmaili S, Esna-Ashari F, Ardalan G, Sepanlou SG, et al. Gender differences in healthy ranges for serum alanine aminotransferase levels in adolescence. PLoS One. 2011;6(6):1-7. 
32. Saghaei M. Random allocation software for parallel group randomized trials. BMC Med Res Methodol. 2004;4:26.

33. Rapisarda P, Fanella F, Maccarone E. Reliability of analytical methods for determining anthocyanins in blood orange juices. J Agric Food Chem. 2000;48(6):2249-52.

34. Somi MH, Banihabib N, Dehghan G, Es. Haghi M, Panahi F. Hepatoprotective Effect of Cornus mas Fruits Extract Against Carbon Tetrachloride-Induced Hepatic Damage in Male Albino Rats. Thrita. 2014;3(2):e17625.

35. Alavian SM, Banihabib N, Es. Haghi M, Panahi F. Protective effect of cornus mas fruits extract on serum biomarkers in CCl4-induced hepatotoxicity in male rats. Hepat Mon. 2014; 14(4):e10330

36. Pehrsson PR, Haytowitz DB, Holden JM, Perry CR, Beckler DG. USDA's national food and nutrient analysis program: Food sampling. J Food Compos Anal. 2000;13(4):379-89.

37. Tran VD, Do VV, Pham NM, Nguyen CT, Xuong NT, Jancey J, et al. Validity of the International Physical Activity Questionnaire-Short Form for Application in Asian Countries: A Study in Vietnam. Eval Heal Prof. 2020;43(2):105-9.

38. Craig CL, Marshall AL, Sjöström M, Bauman AE, Booth ML, Ainsworth BE, et al. International physical activity questionnaire: 12-Country reliability and validity. Med Sci Sports Exerc. 2003;35(8):1381-95.

39. de Pascual-Teresa S, Moreno DA, García-Viguera C. Flavanols and anthocyanins in cardiovascular health: A review of current evidence. Int J Mol Sci. 2010;11(4):1679-703.

40. Clark JL, Zahradka P, Taylor CG. Efficacy of flavonoids in the management of high blood pressure. Nutr Rev. 2015;73(12):799-822.

41. Rani N, Bharti S, Bhatia J, Nag TC, Ray R, Arya DS. Chrysin, a PPAR-y agonist improves myocardial injury in diabetic rats through inhibiting AGE-RAGE mediated oxidative stress and inflammation. Chem Biol Interact. 2016;250:59-67.

42. Godos J, Vitale M, Micek A, Ray S, Martini D, Del Rio D, et al. Dietary polyphenol intake, blood pressure, and hypertension: A systematic review and meta-analysis of observational studies. Antioxidants. 2019;8(6):1-21.

43. Johnson SA, Figueroa A, Navaei N, Wong A, Kalfon R, Ormsbee LT, et al. Daily blueberry consumption improves blood pressure and arterial stiffness in postmenopausal women with pre- and stage 1hypertension: A randomized, double-blind, placebo-controlled clinical trial. J Acad Nutr Diet. 2015;115(3):369-77.

44. Broncel M, Koziróg M, Duchnowicz P, Koter-Michalak M, Sikora J, Chojnowska-Jezierska J. Aronia melanocarpa extract reduces blood pressure, serum endothelin, lipid, and oxidative stress marker levels in patients with metabolic syndrome. Med Sci Monit. 2010;16(1):28-34.

45. Basu A, Du M, Leyva MJ, Sanchez K, Betts NM, Wu M, et al. Blueberries decrease cardiovascular risk factors in obese men and women with metabolic syndrome. J Nutr. 2010;140(9):1582-7.

46. Hassellund SS, Flaa A, Sandvik L, Kjeldsen SE, Rostrup M. Effects of anthocyanins on blood pressure and stress reactivity: A double-blind randomized placebo-controlled crossover study. J Hum Hypertens. 2012;26(6):396-404. 
47. Daneshzad E, Shab-Bidar S, Mohammadpour Z, Djafarian K. Effect of anthocyanin supplementation on cardio-metabolic biomarkers: A systematic review and meta-analysis of randomized controlled trials. Clin Nutr. 2019;38(3):1153-65.

48. Azzini E, Giacometti J, Russo GL. Antiobesity Effects of Anthocyanins in Preclinical and Clinical Studies. Oxid Med Cell Longev. 2017;2017:2740364.

49. Chang JJ, Hsu MJ, Huang HP, Chung DJ, Chang YC, Wang CJ. Mulberry anthocyanins inhibit oleic acid induced lipid accumulation by reduction of lipogenesis and promotion of hepatic lipid clearance. J Agric Food Chem. 2013;61(25):6069-76.

50. Goto T, Teraminami A, Lee JY, Ohyama K, Funakoshi K, Kim Y II, et al. Tiliroside, a glycosidic flavonoid, ameliorates obesity-induced metabolic disorders via activation of adiponectin signaling followed by enhancement of fatty acid oxidation in liver and skeletal muscle in obese-diabetic mice. J Nutr Biochem. 2012;23(7):768-76.

51. Guo H, Li D, Ling W, Feng X, Xia M. Anthocyanin inhibits high glucose-induced hepatic mtGPAT1 activation and prevents fatty acid synthesis through PKCל. J Lipid Res. 2011;52(5):908-22.

52. Peng $\mathrm{CH}$, Chyau $\mathrm{CC}$, Chan KC, Chan TH, Wang $\mathrm{CJ}$, Huang $\mathrm{CN}$. Hibiscus sabdariffa polyphenolic extract inhibits hyperglycemia, hyperlipidemia, and glycation-oxidative stress while improving insulin resistance. J Agric Food Chem. 2011;59(18):9901-9.

53. Lee IT, Chan YC, Lin CW, Lee WJ, Sheu WHH. Effect of cranberry extracts on lipid profiles in subjects with type 2 diabetes. Diabet Med. 2008;25(12):1473-7.

54. Zhang PW, Chen FX, Li D, Ling WH, Guo HH. A CONSORT-Compliant, Randomized, Double-Blind, Placebo-Controlled Pilot Trial of Purified Anthocyanin in Patients with Nonalcoholic Fatty Liver Disease. Med (United States). 2015;94(20):e758.

55. Hernaez R, Lazo M, Bonekamp S, Kamel I, Brancati FL, Guallar E, et al. Diagnostic accuracy and reliability of ultrasonography for the detection of fatty liver: A meta-analysis. Hepatology. 2011;54(3):1082-1090.

56. Eddowes PJ, Sasso M, Allison M, Tsochatzis E, Anstee QM, Sheridan D, et al. Accuracy of FibroScan Controlled Attenuation Parameter and Liver Stiffness Measurement in Assessing Steatosis and Fibrosis in Patients With Nonalcoholic Fatty Liver Disease. Gastroenterology. 2019;156(6):1717-30.

\section{Figures}




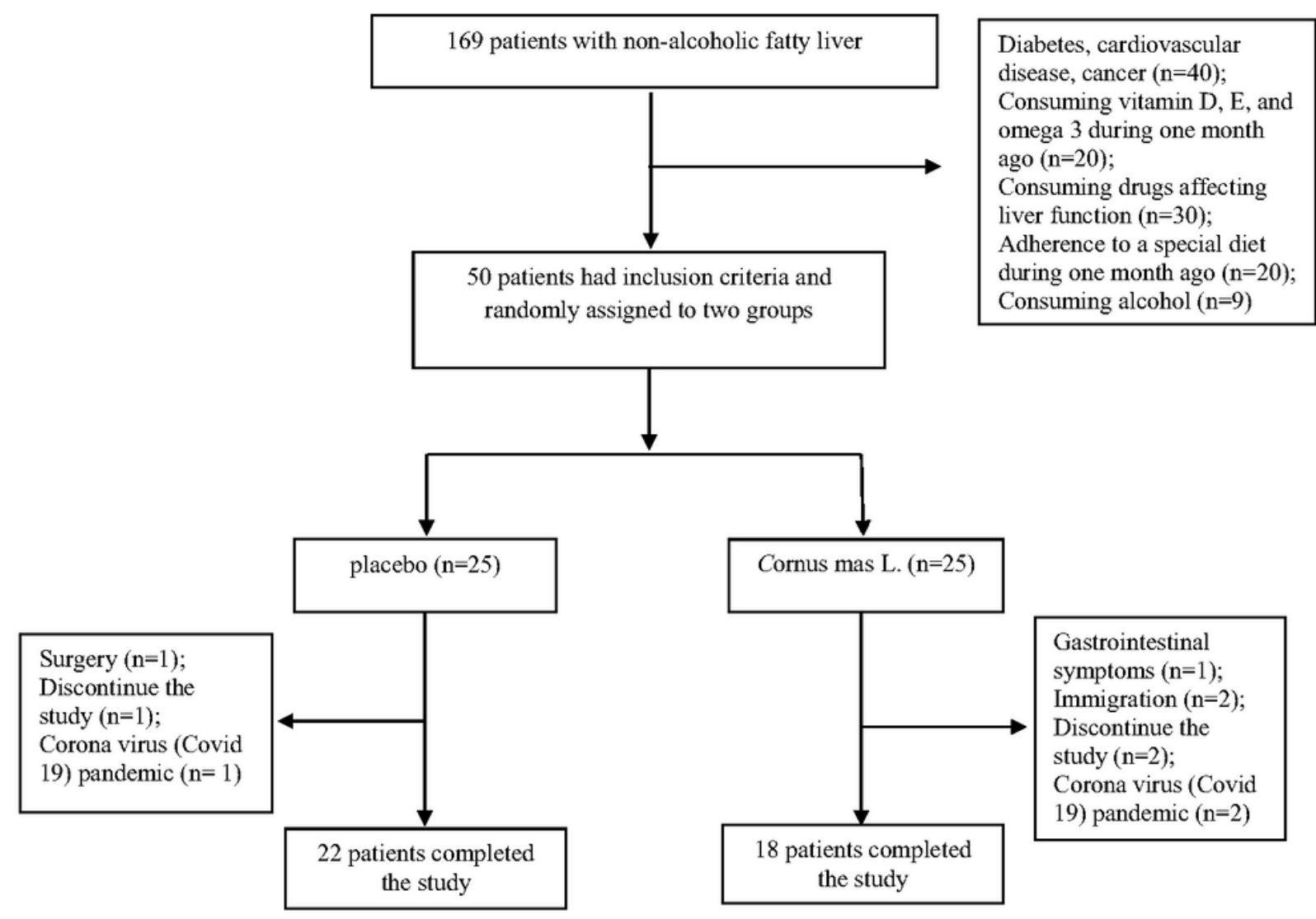

Figure 1

eligibility, screening, and follow-up.

\section{Supplementary Files}

This is a list of supplementary files associated with this preprint. Click to download.

- ConsortChecklist.doc 